Original Article

\title{
ANTIBACTERIAL EFFECTIVENESS OF PROSOPIS JULIFLORA AGAINST AEROBIC AND ANAEROBIC BACTERIA
}

\author{
AISHWARYA V.1 , BHUVANESHWARI G. ${ }^{2}$, J. R. LILLY GRACE ${ }^{3}$, ROSY VENNILA 4 \\ 'Saveetha Medical College and Hospital, ${ }^{2}$ Department of Microbiology, Saveetha Medical College and Hospital, ${ }^{3}$ Medical Microbiology, \\ Saveetha Medical College and Hospital, ${ }^{4}$ Saveetha Medical College and Hospital \\ Email: aishvenkat9600@gmail.com
}

Received: 12 Jul 2020, Revised and Accepted: 09 Sep 2020

\begin{abstract}
Objective: The aim of this study is to analyse the antibacterial effectiveness of the leaf extract of Prosopis juliflora against aerobic and anaerobic bacteria and the objectives include maintaining the culture of Clostridium perfringens ATCC 3624, Staphylococcus aureus ATCC 25923, E. coli ATCC 25922 and to obtain an extract from the leaves of Prosopis juliflora by water extraction method. Agar cup diffusion testing is carried out to test the effectiveness of the extracted herb against the isolated strains of the above-mentioned bacteria.

Methods: Cross-sectional study was conducted for 6 mo in the Clinical Microbiology Laboratory at SMCH. Extract from the leaves of Prosopis juliflora was collected by a water extraction method. Isolation of Clostridium perfringens (from RCMB), Staphylococcus aureus and Escherichia coli were done, following which the agar cup diffusion method was performed in which the collected extracts were placed as discs in the agar plate which had been inoculated with the strains of the isolated bacteria. The agar plate was then incubated anaerobically. Agar cup diffusion method is considered as a primary method to determine the antimicrobial effectiveness of the bacteria.
\end{abstract}

Results: The leaf extract of Prosopis juliflora was found to be effective against both aerobic and anaerobic bacterial strains.

Conclusion: Based on the work, the effectiveness of Prosopis juliflora was determined and the mechanism of susceptibility was identified. With future research works in the field, many such natural herbal extracts can be proven to be effective against many pathogenic microorganisms.

Keywords: Staphylococcus aureus, E. coli, Clostridium perfringens, Antimicrobial susceptibility testing, Robertson cooked meat medium

(C) 2020 The Authors. Published by Innovare Academic Sciences Pvt Ltd. This is an open access article under the CC BY license (http://creativecommons.org/licenses/by/4.0/) DOI: http://dx.doi.org/10.22159/ijcpr.2020v12i6.40305. Journal homepage: https://innovareacademics.in/journals/index.php/ijcpr

\section{INTRODUCTION}

Prosopis juliflora is a shrub or small tree which belongs to the family Fabaceae [1]. It is a kind of mesquite. It is native to Mexico, South America and the Carribean and has become established as an invasive weed in Africa, Asia and Australia.

The results of various studies showed that this plant holds many benefits for the habitual treatment of various maladies and has a wide range of applications as indigenous medicine for several years. This herb is well known in the folkloric system of medicine because of its ethnobotanical importance [2]. The plant has been reported to treat oral ailments like a toothache. The leaves of this plant are used in the treatment of asthma, conjunctivitis, bronchitis and also in skin, blood and venereal diseases and are also found to be useful as an insecticide. The crude extracts of various parts and purified chemical components of this plant have been found to possess insecticidal, antimicrobial and different pharmacological activities against many pathogenic microorganisms [3]. The high-potential activity of these extracts compared to selective antibiotics lead to evaluate the new antimicrobial agents to fight against the drug-resistant pathogens.

Staphylococcus aureus is a gram-positive, aerobic bacterium that is a member of the Firmicutes. It is found to be the most dangerous of all of the many common staphylococcal bacteria. Staphylococcus aureus can cause a range of illnesses from minor skin infections, such as pimples, impetigo, cellulitis, folliculitis, carbuncles, scalded skin syndrome, and abscesses, to life-threatening diseases such as endocarditis pneumonia, osteomyelitis meningitis, toxic shock syndrome, bacteremia, and sepsis.

Clostridium perfringens is a gram-positive, rod-shaped, anaerobic, spore-forming pathogenic bacterium of the genus Clostridium. Clostridium perfringens causes a wide range of symptoms, from food poisoning to cellulitis, fasciitis, necrotic enteritis, tissue necrosis, bacteremia, emphysematous cholecystitis, and gas gangrene also called as clostridial myonecrosis which occurs especially in war zones where the prevalence of this bacterium is high causing increased cases of gas gangrene among the soldiers.

Escherichia coli also is known as Escherichi coli are gram-negative, facultatively anaerobic, rod-shaped, coliform bacteria of the genus Escherichia. Escherichia coli is one of the most frequent causes of many common bacterial infections, including cholecystitis, bacteremia, cholangitis, urinary tract infection (UTI), and traveller's diarrhea, and other clinical infections such as neonatal meningitis and pneumonia.

This study deals with calculating the effectiveness of Prosopis juliflora against aerobic organisms such as Staphylococcus aureus and anaerobic organisms such as Clostridium perfringens and Escherichia coli (facultative anaerobe) using the agar cup diffusion method, which is considered as a primary test for testing effectiveness. Based on the effectiveness, the herb can be utilised in the treatment of diseases caused by these bacteria.

\section{MATERIALS AND METHODS}

The leaves of Prosopis juliflora were collected, washed, dried and crushed to fine powder. The extract of the herb is obtained by hot water method.

\section{Hot water method}

The hot water extraction method is the most widely used extraction method in producing powdered extract.

\section{Step one-hot water processing}

Water is an important and primary extraction solvent used in producing herbal extracts. The powdered herbs were combined with water and were heated to between $100{ }^{\circ} \mathrm{C}$ and $110^{\circ} \mathrm{C}$. This process is called stoving. It was repeated several times. When the hot water extraction process was complete, the solution of herbs and water was vacuum pumped to obtain the desired concentration. The outcome obtained was a highly concentrated combination of extracted herbs and water. 


\section{Step two-alcohol precipitation}

Precipitation of the mixture of herbs and water was done to separate the powdered extract from the water. Alcohol precipitation allows the compounds that have been dissolved in water to be transferred back to the solids. The concentration of herbs and water from step one was combined at a 1:3 ratio with alcohol (95\%ethanol), so that for each part of herbs and water, there were three parts alcohol. This mixture was agitated for $15 \mathrm{~min}$ and then set aside for $12 \mathrm{~h}$ so that the desired compounds were able to be fully extracted into the alcohol. After $12 \mathrm{~h}$, the liquid and the solids were separated-the water and alcohol evaporated, leaving behind their extracts. Finally, the extract was spray-dried at a temperature of $70{ }^{\circ} \mathrm{C}-100{ }^{\circ} \mathrm{C}$, and the resulting powder was further crushed, stirred, and sieved.

After the water extraction of the herb, the isolation of Clostridium perfringens (from RCMB), Staphylococcus aureus and Escherichia coli were carried out.

\section{Isolation of clostridium perfringens: (Atcc 3624) (fig. 1)}

Clinical materials were inoculated deep into Robertson's cooked meat broth (RCMB) medium as per the standard method. It was incubated under the anaerobic condition at $37{ }^{\circ} \mathrm{C}$ for $48 \mathrm{~h}$ [4]. Broth cultures exhibiting production of acid and gas without digestion of meat, sour odour of the culture and reddening of meat, which are considered to be the typical features of Clostridium perfringens were further subcultivated on $5 \%$ sheep blood agar plates and incubated at $37^{\circ} \mathrm{C}$ for $24 \mathrm{~h}$ under anaerobic conditions for proliferation. Isolates were identified as Clostridium Perfringens.

\section{Isolation of $E$. coli: (ATCC 25922)}

Sample suspension was made at $5 \%$ in normal saline or phosphate buffer solution [5]. It was then inoculated onto MacConkey agar which was followed by an incubation period of $18-20 \mathrm{~h}$ at $37^{\circ} \mathrm{C}$. Pink, round, medium-sized colonies are considered as Escherichia coli colonies [6]. Purification of the colonies was done in nondifferential media such as nutrient agar and blood agar. A series of inoculations were carried out until pure, single, or solitary colonies were obtained.

\section{Isolation of staphylococcus aureus: (ATCC 25923)}

The organism was isolated by streaking of the material from blood culture or a clinical specimen onto solid media such as blood agar, tryptic soy agar or heart infusion agar [7]. Incubation of the organism in mannitol salt agar containing $7.5 \%$ sodium chloride allows the growth of halo-tolerant species of staphylococci to grow [8].

With the use of the extracted herbs and isolated strains of Clostridium perfringens, Staphylococcus aureus and Esherichia coli, agar cup diffusion was carried out.

\section{Disk diffusion method}

The disk diffusion test or agar cup diffusion test is an antibiotic sensitivity test. This is also known as the Kirby Bauer test.

\section{Principle}

It uses antibiotic discs or extractions of any herbs to determine the extent to which bacteria are affected by the test antibiotics or the extracted herbs [10]. In this test, discs containing antibiotics or any extracted herbs are placed on an agar plate where bacteria have been placed, and the plate is left to incubate [11]. If an antibiotic stops the bacteria from growing or kills the bacteria, there will be an area around the disc where the bacteria have not grown enough to be visible [12]. This is called a zone of inhibition.

The size of this zone depends on how effective the antibiotic is at stopping the growth of the bacterium and the diffusion of the antibiotic within the agar medium.

\section{Procedure}

Disks of extracted herbs were placed atop of the isolated strains of Clostridium perfringens. The bacteria was then allowed to grow and then observed for growth and effect of the extracted herb on it as it diffused into the agar plate. The amount of space around every disk indicates the effect of the extract on the bacteria $[13,14]$. If the compound is effective against bacteria at a certain concentration, no colonies will grow where the concentration in the agar is greater than or equal to the effective concentration [15]. This is referred to as the zone of inhibition. This, along with the rate of antibiotic diffusion, is used to estimate the bacteria's susceptibility to the extracted herb [16]. Inhibition produced by the herb extract was compared with that produced by the known concentration of a reference compound.

The same procedure was carried out with the isolated strains of Staphylococcus aureus, Esherichia coli and the zone of inhibition produced by the extracted herb against the above-mentioned bacteria was determined. Inhibition produced by the herb extract was compared with that produced by the known concentration of a reference compound [17]. The zone diameter was measured and it was compared to zone standards to determine if the bacteria were susceptible, moderately susceptible, or resistant to the extracted herb [18].

\section{RESULTS}

The extract from the leaves of Prosopis juliflora exhibited antibacterial activity against all three test organisms. The test organisms were found to be sensitive to the herbal extract. The zone of inhibition of aerobic organism was found to be $24 \mathrm{~mm}$ (fig. 2). The zone of inhibition of anaerobic organisms was found to be $18 \mathrm{~mm}$. (fig. 3).

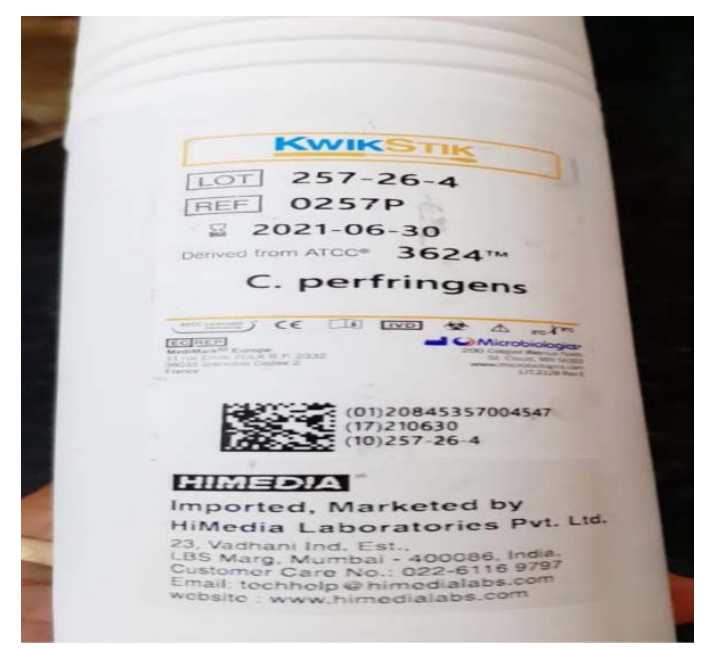

Fig. 1: Clostridium perfringens ATCC 3624 


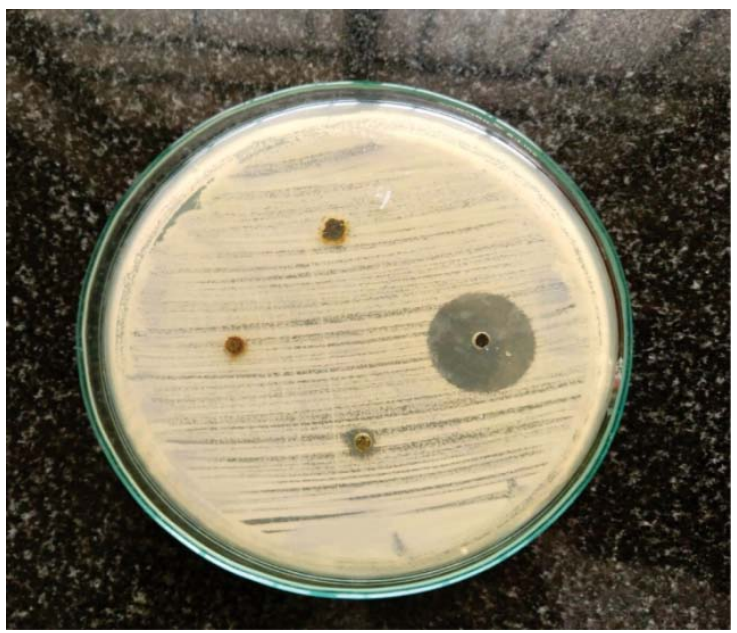

Fig. 2: Antibacterial susceptibility testing of Prosopis juliflora against aerobic bacteria

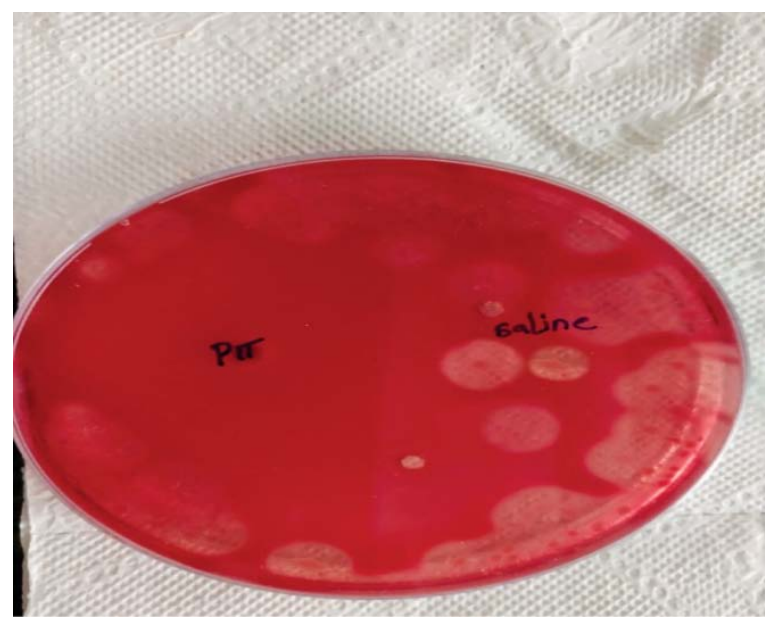

Fig. 3: Antibacterial effectiveness of Prosopis juliflora against anaerobic bacteria

\section{DISCUSSION}

Prosopis juliflora provides several beneficial effects by producing several compounds like alkaloid, tannin, phenolics, steroids, terpenes, flavonoids, proteins, sugars, fatty acids, which are useful in treating diseases ${ }^{1}$. Some of these compounds may exhibit therapeutic activities such as antibacterial activity.

As stated in the study conducted by Prabhas, juliprosinene and juliflorinine isolated from P. juliflora exhibit antibacterial effects on bacteria such as Escherichia coli, Staphylococcus aureus, Klebsiella pneumonia, and Shigella sonnei [19]. In a study conducted by Singh et al., it was found that the antibacterial substances may protect Prosopis juliflora against microorganisms [20].

In the study conducted by Saeed, it was stated that gram-positive organisms were more susceptible to the extract of Prosopis juliflora seedpods than gram-negative organisms [21]. In previous studies it was determined that there is higher susceptibility of gram-positive bacteria to extracts. The less susceptibility of gram-negative bacteria to antibacterial substances can be due to their outer membrane and lipopolysaccharide molecules, which act as a barrier against penetration of many antimicrobial agents.

\section{CONCLUSION}

Based on this study, the antibacterial effectiveness of Prosopis juliflora against many pathogenic organisms was determined, thus proving that it has several therapeutic uses in curing diseases. Multiple drug resistance in human pathogens has been developed rapidly to commonly use antimicrobial drugs to cure diseases caused by pathogens. Hence, discovery of new antibacterial substances, either synthetic or natural with minimal side effects is necessary. Increasing the popularity of plant-based traditional medication among people has led researchers to consider the available option of using natural compounds of plant origin as a valuable source for treating diseases [22]. And, Prosopis juliflora appears to be a promising candidate for further studies on its antibacterial effectiveness (which can be determined by using methods like crystallography) and also in curing diseases.

\section{FUNDING}

Nil

\section{AUTHORS CONTRIBUTIONS}

All the authors have contributed equally.

\section{CONFLICT OF INTERESTS}

Declared none

\section{REFERENCES}

1. Singh S, Swapnil, Verma SK. Antibacterial properties of alkaloid rich fractions obtained from various parts of prosopis juliflora. Int J Pharma Sci Res 2011;2:114-20.

2. Thakur Rupesh, Singh Rupal, Saxena Pooja, Mani Abin. Evaluation of the antibacterial activity of prosopis juliflora (SW.) DC. Leaves. Afr J Traditional Complementary Alternative 
Medicines AJTCAM/African Networks Ethnomedicines 2014; 11:182-8.

3. Ahmad Aqeel, Khan K, Ahmad Viqar, Qazi Sabiha. Antibacterial activity of juliflorine isolated from prosopis juliflora. Planta Med 1986;52:285-8.

4. Boyan Bonev, James Hooper, Judicael Parisot. Principles of assessing bacterial susceptibility to antibiotics using the agar diffusion method. J Antimicrob Chemother 2008;61:1295-301.

5. Hari Prasad O, Aluru S, Kishore Kumar A, Navya A, Hari Krishna O, Bhaskar M, et al. Comparative evaluation of the antibacterial efficacy of $P$. juliflora and three commercially available mouthrinses: an in vitro study. J Pharm Res 2011;4:2149-51.

6. Malik A, Kalidhar SB. A review of the chemistry and biological activity of prosopis species. J Med Arom Plant Sci 2005;27:675705.

7. Navya A, Hari Prasad O, Nanda Kumar Y, Sarma PVGK, Bhaskar M, Devi PUM. Antimicrobial, anti-proliferative activity and identification of drug candidates in phytochemicals of Prosopis juliflora. J Clin Cell Immunol 2011. DOI:10.4172/2155-989910000S1.

8. Prabha DS, Dahms HU, Malliga P. Assessment of acute and subacute oral toxicity of ethanolic extracts of prosopis juliflora on rattus norvegicus. J Herb Med Toxicol 2012;6:61-5.

9. Sathiya M, Muthuchelian K. Investigation of phytochemical profile and antibacterial potential of ethanolic leaf extract of prosopis juliflora DC. Ethnobot Leaflets 2008;12:1240-5.

10. Seetha Lakshmi B, Naidu KOC, Murthy YLN, Bobbarala V, Pandit $\mathrm{N}$. Bio-efficacy of some medicinal plants against pathogens of cereal crops and phytochemical examination of prosopis juliflora (Sw) Dc. J Pharm Res 2010;3:356-60.

11. Sasidharan S, Chen Y, Saravanan D, Sundram KM, Yoga Latha L. Extraction, isolation and characterization of bioactive compounds from plants'extracts. Afr J Tradit Complement Altern Med 2011;8:1-10.

12. Singh S, Swapnil, Verma SK. Antibacterial properties of alkaloid rich fractions obtained from various part of prosopis juliflora. Int J Pharma Sci Res 2011;2:114-20.

13. Taheri A, Seyfan A, Jalalinezhad S, Nasery F. Study of antibacterial effect of prosopis sp. hydro-alcoholic. Extract Pejouhandeh 2012;17:196-202.

14. Aqeel A, Khursheed AK, Viqaruddin A, Sabiha Q. Antimicrobial activity of julifloricine isolated from prosopis juliflora. Arzneimittelforschung 1989;39:652-55

15. Nikaido H. Prevention of drug access to bacterial targets: permeability barriers and active efflux. Science 1994;264:382-8.

16. Kathirvel P, Kumudha P. Chemical composition of prosopis juliflora (sw.) D. C (mosquito bean). Int J Appl Biol Pharma Technol 2011;2:199-209.

17. Del Valle FR, Escobedo M, Munoz MJ, Ortega R, Bourges H. Chemical and nutritional studies on mesquite beans (Prosopis juliflora). J Food Sci 1983;48:914-9.

18. Marangoni A, Alli I. Composition and properties of seeds and pods of the tree legume prosopis juliflora (DC). J Sci Food Agric 1988;44:99-110.

19. Prabha DS, Dahms HU, Malliga P. Pharmacological potentials of phenolic compounds from prosopis spp.-a review. J Coast Life Med 2014;2:918-24.

20. Singh S. Phytochemical analysis of different parts of prosopis juliflora. Int J Curr Pharm Res 2012;4:59-61.

21. Saeed Tajbakhsh, Alireza Barmak, Faezeh Vakhshiteh, Marzieh Gharibi. In vitro Antibacterial activity of the prosopis juliflora seed pods on some common pathogens. J Clin Diagn Res 2015;9:DC13-DC15.

22. Prabha DS, Dahms HU, Malliga P. Pharmacological potentials of phenolic compounds from prosopis spp.-a review. J Coast Life Med 2014;2:918-24 